TITLE:

\title{
Cisplatin, rather than oxaliplatin, increases paracellular permeability of LLC-PK1 cells via activating protein kinase $\mathrm{C}$
}

\author{
$\operatorname{AUTHOR}(\mathrm{S})$ : \\ Zhang, Yunpeng; Yonezawa, Atsushi; Nakagawa, \\ Shunsaku; Imai, Satoshi; Denda, Masaya; Omura, \\ Tomohiro; Nakagawa, Takayuki; Matsubara, Kazuo
}

\section{CITATION:}

Zhang, Yunpeng ... [et al]. Cisplatin, rather than oxaliplatin, increases paracellular permeability of LLC-PK1 cells via activating protein kinase C. Drug Metabolism and Pharmacokinetics 2019, 35(1)

\section{ISSUE DATE:}

2019-09

URL:

http://hdl.handle.net/2433/245791

\section{RIGHT:}

(c) 2020. This manuscript version is made available under the CC-BY-NC-ND 4 . O license

http://creativecommons.org/licenses/by-nc-nd/4.0/.; The full-text file will be made open to the public on 1 February 2021 in accordance with publisher's 'Terms and Conditions for Self-Archiving'..; This is not the published version. Please cite only the published version.; この論文は出版社版でありません。引用の際には出版社版をご確認ご利用ください。 
1 Cisplatin, rather than oxaliplatin, increases paracellular permeability of LLC-PK1 cells via

2 activating protein kinase $\mathrm{C}$

3

4 Yunpeng Zhang ${ }^{1,2}$, Atsushi Yonezawa ${ }^{1,2}$, Shunsaku Nakagawa ${ }^{1}$, Satoshi Imai ${ }^{1}$, Masaya Denda

$5 \quad{ }^{1,2}$, Tomohiro Omura $^{1}$, Takayuki Nakagawa ${ }^{1}$, Kazuo Matsubara $^{1}$

6

$7 \quad{ }^{1}$ Department of Clinical Pharmacology and Therapeutics, Kyoto University Hospital

854 Shogoin Kawahara-cho, Sakyo-ku, Kyoto 606-8507, Japan

$9 \quad{ }^{2}$ Graduate School and Faculty of Pharmaceutical Science, Kyoto University

10 46-29 Yoshida Shimoadachi-cho, Sakyo-ku, Kyoto 606-8501, Japan

11

12 Corresponding author: Atsushi Yonezawa, Ph.D.

54 Shogoin Kawahara-cho 


\section{Abstract}

The clinical use of cisplatin is limited by its adverse events, particularly serious

23 nephrotoxicity. It was clarified that cisplatin is transported by a kidney-specific organic 24 cation transporter (OCT2). OCT2 also mediates the uptake of oxaliplatin into renal proximal 25 tubular cells; however, this agent does not lead nephrotoxicity. In the present study, we 26 carried out comparative experiments with cisplatin and oxaliplatin using porcine kidney LLC27 PK1 cell monolayers. In the fluorescein-labeled isothiocyanate-dextran flux assay, the 28 basolateral application of cisplatin, but not oxaliplatin, resulted in an increase in the 29 paracellular permeability of cell monolayers. Even though the cellular accumulation of 30 platinum at $50 \mu \mathrm{M}$ oxaliplatin could reach the same level at $30 \mu \mathrm{M}$ cisplatin, oxaliplatin did 31 not induce hyper-permeability in cell monolayers. Cisplatin, but not oxaliplatin, significantly 32 activated PKC. In addition, the combination of PKC inhibitors recovered the increase in 33 paracellular permeability. In conclusion, pharmacodynamic mechanisms via PKC could 34 explain the difference in nephrotoxicity between cisplatin and oxaliplatin.

\section{Keywords}

37 Cisplatin, oxaliplatin, nephrotoxicity, protein kinase C, paracellular permeability 


\section{Introduction}

Cisplatin shows a broad spectrum of activity against various cancers and plays a significant function in cancer chemotherapy. Its adverse effects, particularly nephrotoxicity, remain major factors that limit its clinical use in cancer therapy [1,2]. On the other hand, carboplatin shows little nephrotoxicity, even though it produces the same active agent as cisplatin in the cell. Organic cation transporter 2 (OCT2) is predominantly expressed in the basolateral membranes of renal proximal tubular cells and mediates the uptake of cationic drugs [3-7]. Previously, we reported that OCT2 played important roles in kidney accumulation of cisplatin but not carboplatin $[8,9]$. The substrate specificities of OCT2 among platinum agents can determine cisplatin-specific nephrotoxicity.

On the contrary, another platinum-based antitumor drug, oxaliplatin, is also transported by OCT2, but it does not cause any renal toxicity [9]. The active agent of oxaliplatin is different from those of cisplatin and carboplatin. It has been reported that oxaliplatin exhibited a different cytotoxic mechanism(s) from cisplatin in cancer cells [10,11]. For example, mismatch repair proteins and some damage-recognition proteins bind to cisplatin-GG adducts with higher affinity than oxaliplatin-GG adducts [12]. This is thought to contribute to differences in cytotoxicity and to the range of anticancer activity shown by oxaliplatin and cisplatin. Pharmacodynamic but not pharmacokinetic mechanisms could explain the difference in nephrotoxicity between cisplatin and oxaliplatin.

The protein kinase $\mathrm{C}(\mathrm{PKC})$ family consists of 10 related serine/threonine protein kinases, some of which are critical regulators of cell proliferation, survival and death [13]. Its activity and phosphorylation of downstream signals are also associated with regulation of the barrier function of epithelial cells [14-19]. Recently, the PKC family has been shown to attract marked attention regarding cisplatin-induced nephrotoxicity [20-23]. Furthermore, it has been reported that the inhibition of PKC $\delta$ reduces cisplatin-induced nephrotoxicity without 
64 blocking chemotherapeutic efficacy in mouse cancer models [24]. PKC could play an important role in cisplatin-specific nephrotoxicity.

Based on this background, we hypothesized that the intracellular mechanisms of nephrotoxicity differ between cisplatin and oxaliplatin. In the present study, we carried out comparative experiments using LLC-PK1 cell monolayers, an epithelial cell line originated from porcine proximal tubular cells which express organic cation transporters.

\section{Materials and Methods}

\subsection{Materials}

Cisplatin and fluorescein-labeled isothiocyanate (FITC) dextran (average mol. wt.: 4,000) were purchased from Sigma-Aldrich Co. (St. Louis, USA). Oxaliplatin, sotrastaurin, GF109203X and Go6976 were purchased from Wako Pure Chemical Industries Ltd. (Osaka, Japan). Rottlerin was obtained from Abcam (Cambridge, UK). Cimetidine was purchased from Nacalai Tesque, Inc. (Kyoto, Japan). All other compounds used were of the highest purity available.

\subsection{Cell Culture and Drug Treatment}

LLC-PK1 cells (JCRB Cell Bank, Osaka, Japan) were cultured as described previously [25]. In general, cells were seeded on 6 -well polycarbonate membrane filters $(3-\mu \mathrm{m}$ pores, 4.71- $\mathrm{cm}^{2}$ growth area) inside transwell ${ }^{@}$ cell culture chambers (Corning, Cambridge, MA, USA) at a density of $1.8 \times 10^{6}$ cells/well. The cells were used for the experiments on the 6 th day after seeding. Cell monolayers were incubated in the culture medium with 10, 30 and 50 $\mu \mathrm{M}$ cisplatin or oxaliplatin added to the basolateral side at $37^{\circ} \mathrm{C}$. When inhibitors were used in experiments, they were added to the basolateral side with cisplatin. 

coupled plasma-mass spectrometry (ICP-MS) Agilent7700/MassHunter, Agilent

\subsection{FITC-Dextran Flux Assay}

Paracellular permeability of FITC-dextran was measured using monolayer cultures grown in transwell@ chambers, as described previously with some modification [26]. The cell monolayers were incubated in culture medium with cisplatin or oxaliplatin. After removal of the culture medium from both sides of the monolayers, the cells were incubated with incubation buffer $(2 \mathrm{~mL}$ each side, $\mathrm{pH} 7.4$ buffer on the basolateral side and $\mathrm{pH} 6.0$ buffer on the apical side) at $37^{\circ} \mathrm{C}$ for $10 \mathrm{~min}$. Then, $2 \mathrm{~mL}$ of incubation buffer $(\mathrm{pH} 7.4)$ containing FITC-dextran $(50 \mu \mathrm{M})$ was added to the basolateral side and $2 \mathrm{~mL}$ of incubation buffer (pH $6.0)$ to the apical side. For paracellular flux measurement, the incubation buffer on the apical side was taken at specific time-points $(5,15$ and $30 \mathrm{~min})$. The fluorescence intensity of FITC-dextran at $585 \mathrm{~nm}$ in the buffer was determined with an excitation wavelength of 485 nm using a Mithras LB 940 multimode microplate reader (Berthold Technologies, Bad Wildbad, Germany).

\subsection{Cellular Platinum Uptake Experiment}

For measurement of platinum accumulated in cells, uptake studies were performed as described previously [27]. The cell monolayers were incubated in culture medium with cisplatin or oxaliplatin for 1 hour. After removal of the culture medium from both sides of the monolayers, cells were rapidly washed twice with ice-cold incubation buffer containing $3 \%$ bovine serum albumin and then washed three times with ice-cold incubation buffer. The filters with monolayers were detached from chambers, the cells on the filters were solubilized in $0.5 \mathrm{~mL}$ of $0.5 \mathrm{~N} \mathrm{NaOH}$, and the amount of platinum was determined using inductively

113 Technologies, California, USA). The protein contents of solubilized cells were determined by 
114 the method of Bradford with a Bio-Rad Protein Assay Kit (Bio-Rad Laboratories, Hercules, 115 CA, USA).

\subsection{PKC Kinase Activity Assay}

118 The amount of PKC kinase activity in each sample was measured using a specific PKC 119 assay kit (ab139437, Abcam, Cambridge, UK) according to the manufacturer's instructions.

120 Cell monolayers were incubated in a culture medium with cisplatin or oxaliplatin for 2 hours.

121 After removal of the culture medium from both sides of the monolayers, cells were 122 homogenized with lysis buffer and centrifuged at $13,000 \mathrm{~g}$ for $15 \mathrm{~min}$ at $4^{\circ} \mathrm{C}$. Supernatants 123 were used for the assay with the kit; the absorbance was measured at $450 \mathrm{~nm}$ using a 124 VERSAmax tunable microplate reader (Molecular Devices, San Jose, CA, USA).

\subsection{Lactate Dehydrogenase Release (LDH) Assay}

127 The cytotoxicity of cisplatin was measured with monolayer cultures grown in transwell@ 128 chambers using a LDH Cytotoxicity Detection Kit (Takara, Shiga, Japan), as described 129 previously with some modification [8]. Cells were incubated in the medium containing 130 cisplatin with or without rottlerin for 24 hours. After the incubation, the medium was 131 collected, and the lactate dehydrogenase activity in the medium was measured, according to 132 the manufacturer's instructions.

\subsection{Statistical Analysis}

135 Data are expressed as the mean \pm S.D. Data were analyzed using the unpaired Student's t136 test or multiple comparisons with Dunnett's two-tailed test after a one-way ANOVA.

137 Probability values of less than 0.05 were considered to be statistically significant. 


\section{Results}

3.1. Paracellular Permeability of FITC-Dextran in LLC-PK1 Cell Monolayers after

\section{Cisplatin Exposure}

143 Paracellular permeability of FITC-dextran was evaluated in LLC-PK1 cell monolayers 144 treated with cisplatin for 24 hours. The basal-to-apical flux of FITC-dextran in monolayers 145 with cisplatin was much larger than that in control monolayers, and its rate was nearly 146 constant up to $30 \mathrm{~min}$ (Fig. 1a). The effect of the cisplatin exposure duration was also 147 determined. Compared with the control group, significant increases of FITC-dextran flux at 14830 min were observed in the cell monolayers treated with cisplatin for 10 and 24 hours (Fig. 149 1b).

3.2. Comparative Studies between Cisplatin and Oxaliplatin Using LLC-PK1 Cell

\section{Monolayers}

The cytotoxicities of cisplatin and oxaliplatin were compared by FITC-dextran flux assay.

154 Cell monolayers treated with 30 or $50 \mu \mathrm{M}$ cisplatin became more permeable to FITC-dextran, 155 while oxaliplatin-treated cell monolayers showed little permeability to FITC-dextran (Fig. 2).

156 The cellular accumulation of platinum was examined in LLC-PK1 cells treated with 157 cisplatin or oxaliplatin (Fig. 3). Then, accumulation of cisplatin increased in a dose158 dependent manner, whereas slight increases in oxaliplatin accumulation were also observed. 159 The uptakes of cisplatin at 30 and $50 \mu \mathrm{M}$ were larger than those of oxaliplatin at 160 corresponding concentrations, although that of oxaliplatin at $50 \mu \mathrm{M}$ reached the same level as 161 the cellular accumulation of cisplatin at $30 \mu \mathrm{M}$.

162 PKC activities were measured in LLC-PK1 cell monolayers using a PKC kinase activity 163 assay kit. As a result, cisplatin, but not oxaliplatin, significantly activated PKC (Fig. 4a), and 
164 the activation of PKC was increased in a dose-dependent manner as well as the FITC-dextran 165 permeability increased by cisplatin (Fig. 4b).

\subsection{Effect of Inhibitors in LLC-PK1 Cell Monolayers}

The inhibitory effects of PKC inhibitors on cisplatin-induced hyper-permeability were examined in LLC-PK1 cell monolayers. Sotrastaurin (AEB071, $5 \mu \mathrm{M})$, GF109203X (GFX, 2 $\mu \mathrm{M})$, and rottlerin significantly inhibited the cisplatin-induced hyper-permeability. Go6976

$171(3 \mu \mathrm{M})$ showed a weaker inhibitory effect compared with the other PKC inhibitors (Fig. 5a).

172 These inhibitors also reduced the PKC activation increased by cisplatin (Fig. 5b). However, 173 rottlerin did not affect the LDH release in LLC-PK1 cell monolayers treated with $30 \mu \mathrm{M}$ 174 cisplatin $(31.9 \pm 5.5 \%$ vs $41.8 \pm 2.9 \%)$.

175 The inhibitory effects of an OCT2 inhibitor, cimetidine, on paracellular permeability and 176 cellular accumulation in cell monolayers were studied. Both the fluxes of FITC-dextran (Fig. 177 6a) and intracellular accumulation of cisplatin (Fig. 6b) in LLC-PK1 cell monolayers were 178 significantly decreased by co-treatment with cimetidine. On the other hand, rottlerin did not 179 reduce the cellular accumulation of platinum $(0.12 \pm 0.01 \mathrm{nmol} / \mu \mathrm{g}$ protein $\mathrm{vs} 0.14 \pm 0.01$ $180 \mathrm{nmol} / \mu \mathrm{g}$ protein).

\section{Discussion}

184 In the present study, we carried out comparative experiments using LLC-PK1 cell 185 monolayers to demonstrate that cisplatin and oxaliplatin exhibited differential cytotoxic 186 mechanisms in the kidney. It was shown that the basolateral application of cisplatin, but not 187 oxaliplatin, resulted in an increase in paracellular permeability of cell monolayers. Cisplatin 188 but not oxaliplatin induced PKC activation in cells. Although accumulated platinum in cells 
189 reached the same level when cisplatin or oxaliplatin was exposed at 30 and $50 \mu \mathrm{M}$, 190 respectively, the hyper-permeability was only observed in cell monolayers treated with 191 cisplatin. In addition, the combination of PKC inhibitors recovered the increase in 192 paracellular permeability induced by cisplatin. These results strongly suggest that 193 pharmacodynamic mechanisms via PKC could explain the difference in nephrotoxicity 194 between cisplatin and oxaliplatin.

195 Several molecular mechanisms leading to cytotoxicity have been suggested to be involved in platinum-based antitumor agent treatments against tumor cells, such as DNA damage, 197 mitochondrial dysfunction, and signal responses to DNA damage [2,28]. In recent years, it 198 has been reported that PKC is activated in response to cisplatin [29]. We confirmed that 199 cisplatin, but not oxaliplatin, enhanced PKC activity in LLC-PK1 cell monolayers. It was 200 also demonstrated that cimetidine recovered the hyper-permeability, suggesting that cisplatin 201 entered the cells via OCT2 and activated PKC. To distinguish the subtype of PKC, several 202 inhibitors were used in the FITC-dextran flux assay. Sotrastaurin [30,31] and GF109203X $203[32,33]$ have been reported to be inhibitors of both classical $(\alpha, \beta I, \beta I I, \gamma)$ and novel $(\delta, \varepsilon, \theta, \eta)$ 204 PKC. Both of them made largely recoveries from the hyper-permeability induced by cisplatin 205 exposure. Go6976 [34,35], an inhibitor of classical PKC, showed a weaker inhibitory effect 206 than the others. Although the selectivity of rottlerin in inhibiting the PKC $\delta$ isoform has 207 recently been questioned [36-39], rottlerin showed a potent inhibitory effect on cisplatin208 induced hyper-permeability in the present study. These results suggest that novel PKC, $\$ 09$ particularly $\mathrm{PKC} \delta$, could be one of major factors in cisplatin-specific nephrotoxicity.

210 Renal epithelial cells, such as LLC-PK1, show extensive lateral interdigitations between 211 neighboring cells. Evaluation of cell-to-cell connections can be useful as an in vitro 212 cytotoxicity assay. There are several techniques, such as measurements of 213 transepithelial/transendothelial electrical resistance (TEER) and the permeability of labeled 
214 marker molecules, are widely accepted to measure the integrity of tight junction dynamics 215 [40,41]. It has also been reported that the basolateral application of cisplatin significantly 216 reduces the TEER of MDCK-C7 cell monolayers [42]. Similarly, in the present study, 217 cisplatin increased the paracellular permeability of FITC-dextran by PKC kinase activation in 218 LLC-PK1 cell monolayers however, the molecular mechanism underlying hyper-permeability 219 via PKC pathway remains unclear. Oxaliplatin did not increase the paracellular permeability. 220 On the other hand, our previous study has shown that cisplatin and oxaliplatin induces 221 cytotoxicity evaluated by the lactate dehydrogenase release assay in HEK293 cells expressing 222 OCT2 [9]. In addition, oxaliplatin shows more potent cytotoxicity than cisplatin against 223 human tumor cells by conventional cytotoxicity assays [43-45]. These results suggested that 224 oxaliplatin could show a different cytotoxic mechanism(s) from cisplatin in tumor cells and 225 normal tissues. Evaluation of cell-to-cell connections can be useful as in vitro nephrotoxicity 226 assay to measure the cisplatin-induced nephrotoxicity.

227 In conclusion, cisplatin activated PKC and induced tight junction disruption in renal 228 epithelial cells, while oxaliplatin did not. Pharmacodynamic mechanisms, but not 229 pharmacokinetic mechanisms, may explain the difference in nephrotoxicity between cisplatin 230 and oxaliplatin.

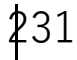

\section{Author contributions}

Wrote Manuscript: YZ, AY, KM

Designed Research: AY

Performed Research: YZ, AY, SN, SI

Analyzed Data: YZ, AY, DM, TO, TN 


\section{Conflicts of interest}

240 The authors declare no conflicts of interest associated with this manuscript.

241

\section{Acknowledgement}

243 This study was supported in part by a Grant-in-Aid for Scientific Research (KAKENHI)

244 from the Ministry of Education, Culture, Sports, Science and Technology of Japan. 


\section{References}

247 [1] Decatris MP, Sundar S, O’Byrne KJ. Platinum-based chemotherapy in metastatic breast cancer: current status. Cancer Treatment Reviews 2004;30:53-81. doi:10.1016/S0305-7372(03)00139-7.

250 [2] Pabla N, Dong Z. Cisplatin nephrotoxicity: Mechanisms and renoprotective strategies. Kidney International 2008;73:994-1007. doi:10.1038/sj.ki.5002786. Okuda M, Saito H, Urakami Y, Takano M, Inui K. cDNA cloning and functional expression of a novel rat kidney organic cation transporter, OCT2. Biochem Biophys Res Commun 1996;224:500-7. doi:http://doi.org/10.1006/bbrc.1996.1056

[4] Urakami Y, Okuda M, Masuda S, Saito H, Inui KI. Functional characteristics and membrane localization of rat multispecific organic cation transporters, OCT1 and OCT2, mediating tubular secretion of cationic drugs. J Pharmacol Exp Ther $1998 ; 287: 800-5$.

[5] Inui KI, Masuda S, Saito H. Cellular and molecular aspects of drug transport in the kidney. Kidney International 2000;58:944-58. doi:10.1046/j.15231755.2000.00251.x.

262 [6] Sugawara-Yokoo M, Urakami Y, Koyama H, Fujikura K, Masuda S, Saito H, et al. Differential localization of organic cation transporters rOCT1 and rOCT2 in the basolateral membrane of rat kidney proximal tubules. Histochem Cell Biol 2000;114:175-80. doi:10.1007/s004180000186.

266 [7] Urakami Y, Okuda M, Masuda S, Akazawa M, Saito H, Inui K. Distinct characteristics of organic cation transporters, OCT1 and OCT2, in the basolateral membrane of renal tubules. Pharm Res 2001;18:1528-34. 
270 [8] Yonezawa A, Masuda S, Nishihara K, Yano I, Katsura T, Inui K-I. Association between tubular toxicity of cisplatin and expression of organic cation transporter rOCT2 (Slc22a2) in the rat. Biochem Pharmacol 2005;70:1823-31. doi:10.1016/j.bcp.2005.09.020.

274 [9] Yonezawa A, Masuda S, Yokoo S, Katsura T, Inui K-I. Cisplatin and oxaliplatin, but not carboplatin and nedaplatin, are substrates for human organic cation transporters (SLC22A1-3 and multidrug and toxin extrusion family). J Pharmacol Exp Ther 2006;319:879-86. doi:10.1124/jpet.106.110346.

278 [10] Wang D, Lippard SJ. Cellular processing of platinum anticancer drugs. Nature Reviews Drug Discovery 2005;4:307-20. doi:10.1038/nrd1691.

280 [11] Kelland L. The resurgence of platinum-based cancer chemotherapy. Nat Rev Cancer 2007;7:573-84. doi:10.1038/nrc2167.

282 [12] Chaney SG, Campbell SL, Bassett E, Wu Y. Recognition and processing of cisplatinand oxaliplatin-DNA adducts. Crit Rev Oncol Hematol 2005;53:3-11. doi:10.1016/j.critrevonc.2004.08.008.

[13] Reyland ME. Protein kinase C isoforms: Multi-functional regulators of cell life and death. Front Biosci (Landmark Ed) 2009;14:2386-99.

287 [14] Banan A, Zhang LJ, Shaikh M, Fields JZ, Choudhary S, Forsyth CB, et al. theta Isoform of protein kinase $\mathrm{C}$ alters barrier function in intestinal epithelium through modulation of distinct claudin isotypes: a novel mechanism for regulation of permeability. J Pharmacol Exp Ther 2005;313:962-82. doi:10.1124/jpet.104.083428.

291 [15] Koizumi JI, Kojima T, Ogasawara N, Kamekura R, Kurose M, Go M, et al. Protein Kinase C Enhances Tight Junction Barrier Function of Human Nasal Epithelial Cells in Primary Culture by Transcriptional Regulation 2008;74:432-42. 
295 [16] Groschwitz KR, Hogan SP. Intestinal barrier function: Molecular regulation and disease pathogenesis 2009;124:3-20. doi:10.1016/j.jaci.2009.05.038.

297 [17] Boratkó A, Csortos C. PKC mediated phosphorylation of TIMAP regulates PP1c activity and endothelial barrier function. Biochim Biophys Acta Mol Cell Res 2017;1864:431-9. doi:10.1016/j.bbamcr.2016.12.001.

300 [18] Ogasawara N, Kojima T, Go M, Ohkuni T, Koizumi J-I, Kamekura R, et al. PPARgamma agonists upregulate the barrier function of tight junctions via a PKC pathway in human nasal epithelial cells. Pharmacol Res 2010;61:489-98. doi:10.1016/j.phrs.2010.03.002.

304 [19] Clarke H, Soler AP, Mullin JM. Protein kinase C activation leads to dephosphorylation of occludin and tight junction permeability increase in LLC-PK1 epithelial cell sheets. Journal of Cell Science 2000;113 ( Pt 18):3187-96.

[20] Zhang J-G, Lindup WE. Cisplatin-induced nephrotoxicity in vitro: increases in cytosolic calcium concentration and the inhibition of cytosolic and mitochondrial protein kinase C. Toxicology Letters 1996;89:11-7. doi:10.1016/S03784274(96)03776-9.

311 [21] Ikeda S, Fukuzaki A, Kaneto H, Ishidoya S, Orikasa S. Role of protein kinase C in cisplatin nephrotoxicity. Int J Urol 1999;6:245-50. doi/10.1046/j.14422042.1999.00058.x

314 [22] Jaiman S, Sharma AK, Singh K, Khanna D. Signalling mechanisms involved in renal pathological changes during cisplatin-induced nephropathy. European Journal of Pharmacology 2013;69:1863-74. doi:10.1007/s00228-013-1568-7.

317 [23] van de Water B, Tijdens IB, Verbrugge A, Huigsloot M, Dihal AA, Stevens JL, et al. Cleavage of the actin-capping protein alpha -adducin at Asp-Asp-Ser-Asp633-Ala by caspase- 3 is preceded by its phosphorylation on serine 726 in cisplatin-induced 
apoptosis of renal epithelial cells. J Biol Chem 2000;275:25805-13. doi:10.1074/jbc.M001680200.

322 [24] Pabla N, Dong G, Jiang M, Huang S, Kumar MV, Messing RO, et al. Inhibition of PKC $\delta$ reduces cisplatin-induced nephrotoxicity without blocking chemotherapeutic efficacy in mouse models of cancer. J Clin Invest 2011;121:2709-22. doi:10.1172/JCI45586.

[25] Urakami Y, Kimura N, Okuda M, Masuda S, Katsura T, Inui K-I. Transcellular transport of creatinine in renal tubular epithelial cell line LLC-PK1. Drug Metab Pharmacokinet 2005;20:200-5. doi:10.2133/dmpk.20.200.

[26] Matsuo Y, Yano I, Ito T, Hashimoto Y, Inui K. Transport of quinolone antibacterial drugs in a kidney epithelial cell line, LLC-PK1. J Pharmacol Exp Ther $1998 ; 287: 672-8$.

[27] Yokoo S, Yonezawa A, Masuda S, Fukatsu A, Katsura T, Inui K-I. Differential contribution of organic cation transporters, OCT2 and MATE1, in platinum agentinduced nephrotoxicity. Biochem Pharmacol 2007;74:477-87. doi:10.1016/j.bcp.2007.03.004.

336 [28] Miller RP, Tadagavadi RK, Ramesh G, Reeves WB. Mechanisms of Cisplatin Nephrotoxicity. Toxins 2010;2:2490-518. doi:10.3390/toxins2112490.

[29] Muscella A, Vetrugno C, Antonaci G, Cossa LG, Marsigliante S. PKC- $\delta /$ PKC- $\alpha$ activity balance regulates the lethal effects of cisplatin. Biochem. Pharmacol 2015;98:29-40. doi:10.1016/j.bcp.2015.08.103.

341 [30] Wu X, Li J, Zhu M, Fletcher JA, Hodi FS. Protein kinase C inhibitor AEB071 targets ocular melanoma harboring GNAQ mutations via effects on the PKC/Erk1/2 and PKC/NF-אB pathways. Mol Cancer Ther 2012;11:1905-14. doi:10.1158/1535- 
345 [31] Hung C-H, Chan S-H, Chu P-M, Tsai K-L. Docetaxel Facilitates Endothelial Dysfunction through Oxidative Stress via Modulation of Protein Kinase C Beta: The Protective Effects of Sotrastaurin. Toxicol Sci 2015;145:59-67. doi:10.1093/toxsci/kfv017.

[32] Marano CW, Laughlin KV, Russo LM, Mullin JM. The protein kinase C inhibitor, bisindolylmaleimide, inhibits the TPA-induced but not the TNF-induced increase in LLC-PK1 transepithelial permeability. Biochemical and Biophysical Research Communications 1995;209:669-76. doi:10.1006/bbrc.1995.1551.

[33] Yang J, Zhang K, Wu J, Shi J, Xue J, Li J, et al. Wnt5a Increases Properties of Lung Cancer Stem Cells and Resistance to Cisplatin through Activation of Wnt5a/PKC Signaling Pathway. Stem Cells Int 2016;2016:1690896-16. doi:10.1155/2016/1690896.

[34] Martiny-Baron G, Kazanietz MG, Mischak H, Blumberg PM, Kochs G, Hug H, et al. Selective inhibition of protein kinase C isozymes by the indolocarbazole Gö 6976. J Biol Chem 1993;268:9194-7.

[35] Parmentier JH. Calcium and Protein Kinase C (PKC)-Related Kinase Mediate alpha 1A-Adrenergic Receptor-Stimulated Activation of Phospholipase D in Rat-1 Cells, Independent of PKC. J Pharmacol Exp Ther 2002;303:1206-15. doi:10.1124/jpet.102.041384.

[36] Soltoff SP. Rottlerin: an inappropriate and ineffective inhibitor of PKCdelta. Trends in Pharmacological Sciences 2007;28:453-8. doi:10.1016/j.tips.2007.07.003.

[37] Davies SP, Reddy H, Caivano M, Cohen P. Specificity and mechanism of action of some commonly used protein kinase inhibitors. Biochem J 2000;351:95-105. doi:10.1042/bj3510095. 
369 [38] Bazuine M, van der Zon GCM, van de Ven R, van den Broek PJA, Antonie Maassen J. Rottlerin inhibits multiple steps involved in insulin-induced glucose uptake in 3T3L1 adipocytes. Biochem Pharmacol 2004;68:105-12. doi:10.1016/j.bcp.2004.02.032.

372 [39] Inoki K, Zhu T, Guan K-L. TSC2 mediates cellular energy response to control cell growth and survival. Cell 2003;115:577-90. doi:http://doi.org/10.1016/S00928674(03)00929-2

[40] Srinivasan B, Kolli AR, Esch MB, Abaci HE, Shuler ML, Hickman JJ. TEER measurement techniques for in vitro barrier model systems. J Lab Autom 2015;20:107-26. doi:10.1177/2211068214561025.

[41] Horibe Y, Hosoya K, Kim KJ, Ogiso T, Lee VH. Polar solute transport across the pigmented rabbit conjunctiva: size dependence and the influence of 8-bromo cyclic adenosine monophosphate. Pharm Res 1997;14:1246-51. doi:10.1023/A:1012123411343.

[42] Ludwig T, Riethmüller C, Gekle M, Schwerdt G, Oberleithner H. Nephrotoxicity of platinum complexes is related to basolateral organic cation transport. Kidney International 2004;66:196-202. doi:10.1111/j.1523-1755.2004.00720.x.

[43] Rixe O, Ortuzar W, Alvarez M, Parker R, Reed E, Paull K, et al. Oxaliplatin, tetraplatin, cisplatin, and carboplatin: Spectrum of activity in drug-resistant cell lines and in the cell lines of the national cancer institute's anticancer drug screen panel. Biochem Pharmacol 1996;52:1855-65. doi:10.1016/S0006-2952(97)81490-6.

[44] Raymond E, Buquet-Fagot C, Djelloul S, Mester J, Cvitkovic E, Allain P, et al. Antitumor activity of oxaliplatin in combination with 5-fluorouracil and the thymidylate synthase inhibitor AG337 in human colon, breast and ovarian cancers. Anticancer Drugs 1997;8:876-85. 
393 [45] Faivre S, Res JWPAAC. Oxaliplatin effects on DNA integrity and apoptosis induction in human tumor cells. Biochem Pharmacol 2003;66:225-237. doi:10.1016/S0006-2952(03)00260-0. 
397

398

399

400

401

402

403

404

405

406

407 408

\section{Figure Legends}

Fig. 1 Paracellular permeability of FITC-dextran in LLC-PK1 cell monolayers after cisplatin exposure. (a) LLC-PK1 cells were incubated in culture medium with $30 \mu \mathrm{M}$ cisplatin added to the basolateral side for 24 hours at $37^{\circ} \mathrm{C}$. The cell monolayers were incubated in the buffer containing $50 \mu \mathrm{M}$ FITC-dextran added to the basolateral side. The fluorescence intensity of FTIC-dextran on the opposite side was periodically measured. Cell monolayers were incubated in culture medium with $30 \mu \mathrm{M}$ cisplatin for $1,2,6,10$, and 24 hours at $37^{\circ} \mathrm{C}$. The cell monolayers were incubated in the buffer containing $50 \mu \mathrm{M}$ FITCdextran added to the basolateral side. The fluorescence intensity of FTIC-dextran on the opposite side was measured at $30 \mathrm{~min}$. Each point and each bar represent the mean $\pm \mathrm{SD}$ of three monolayers. ${ }^{* *} \mathrm{P}<0.01,{ }^{* * *} \mathrm{P}<0.001$, significantly different from control cells.

Fig. 2 Effect of cisplatin and oxaliplatin on paracellular permeability in LLC-PK1 cell monolayers. Cell monolayers were incubated in culture medium with 10,30 , and $50 \mu \mathrm{M}$ cisplatin or oxaliplatin added to the basolateral side for 24 hours at $37^{\circ} \mathrm{C}$. The cell monolayers were incubated in the buffer containing $50 \mu \mathrm{M}$ FITC-dextran added to the basolateral side. The fluorescence intensity of FTIC-dextran on the opposite side was measured at $30 \mathrm{~min}$. Each bar represents the mean $\pm \mathrm{SD}$ of three monolayers. $* \mathrm{P}<0.05$, $* * * \mathrm{P}<0.001$

Fig. 3 Concentration-dependence of platinum accumulation in LLC-PK1 cell monolayers. Cell monolayers were incubated in culture medium with 10,30 , and $50 \mu \mathrm{M}$ cisplatin or oxaliplatin added to the basolateral side for 1 hour at $37^{\circ} \mathrm{C}$. The amount of platinum in the cells was determined by ICP-MS. Each bar represents the mean $\pm \mathrm{SD}$ of three monolayers. $* * \mathrm{P}<0.01, * * * \mathrm{P}<0.001$. 
423 Fig. 4 PKC kinase activity induced by cisplatin and oxaliplatin. LLC-PK1 cell monolayers

424 were incubated in culture medium (a) with 30 cisplatin or oxaliplatin or (b) with 10, 30, and $42550 \mu \mathrm{M}$ cisplatin or oxaliplatin added to the basolateral side for 2 hours at $37^{\circ} \mathrm{C}$. PKC kinase 426 activity in cell monolayers was measured. Each bar represents the mean \pm SD of four 427 monolayers. $* * \mathrm{P}<0.01, * * * \mathrm{P}<0.001$, significantly different from control cells.

LLC-PK1 cell monolayers were incubated in culture medium with $30 \mu \mathrm{M}$ cisplatin added to 431 the basolateral side in the presence or absence of sotrastaurin (AEB071, $5 \mu \mathrm{M}$ ), GF109203X 432 (GFX, $2 \mu \mathrm{M})$, Go6976 $(3 \mu \mathrm{M})$, or rottlerin (ROT, $10 \mu \mathrm{M})$ for 24 hours at $37^{\circ} \mathrm{C}$. The cell 433 monolayers were preincubated in the incubation buffer for $10 \mathrm{~min}$ and then were incubated in 434 the buffer containing $50 \mu \mathrm{M}$ FITC-dextran added to the basolateral side. The fluorescence 435 intensity of FTIC-dextran on the opposite side was measured at $30 \mathrm{~min}$. (b) Cell monolayers 436 were incubated in culture medium with $30 \mu \mathrm{M}$ cisplatin added to the basolateral side in the 437 presence or absence of inhibitors for 2 hours at $37^{\circ} \mathrm{C}$. PKC kinase activity in cell monolayers 438 was measured. $* * * \mathrm{P}<0.001$, significantly different from cisplatin-treated cells.

440 Fig. 6 Effect of cimetidine on paracellular permeability and platinum accumulation in

441 LLC-PK1 cell monolayers treated with cisplatin. (a) Cell monolayers were incubated in 442 culture medium with $30 \mu \mathrm{M}$ cisplatin added to the basolateral side in the presence or absence 443 of $1 \mathrm{mM}$ cimetidine for 24 hours at $37^{\circ} \mathrm{C}$. The cell monolayers were incubated in the buffer 444 containing $50 \mu \mathrm{M}$ FITC-dextran added to the basolateral side. The fluorescence intensity of 445 FTIC-dextran on the opposite side was measured at $30 \mathrm{~min}$. Each bar represents the mean \pm 
447 culture medium with $30 \mu \mathrm{M}$ cisplatin added to the basolateral side in the presence or absence

448 of $1 \mathrm{mM}$ cimetidine for 1 hour at $37^{\circ} \mathrm{C}$. The amount of platinum in the cells was determined 449 by ICP-MS. Each bar represents the mean \pm SD of three monolayers. $* * * \mathrm{P}<0.001$. 
Figure 1

(a)
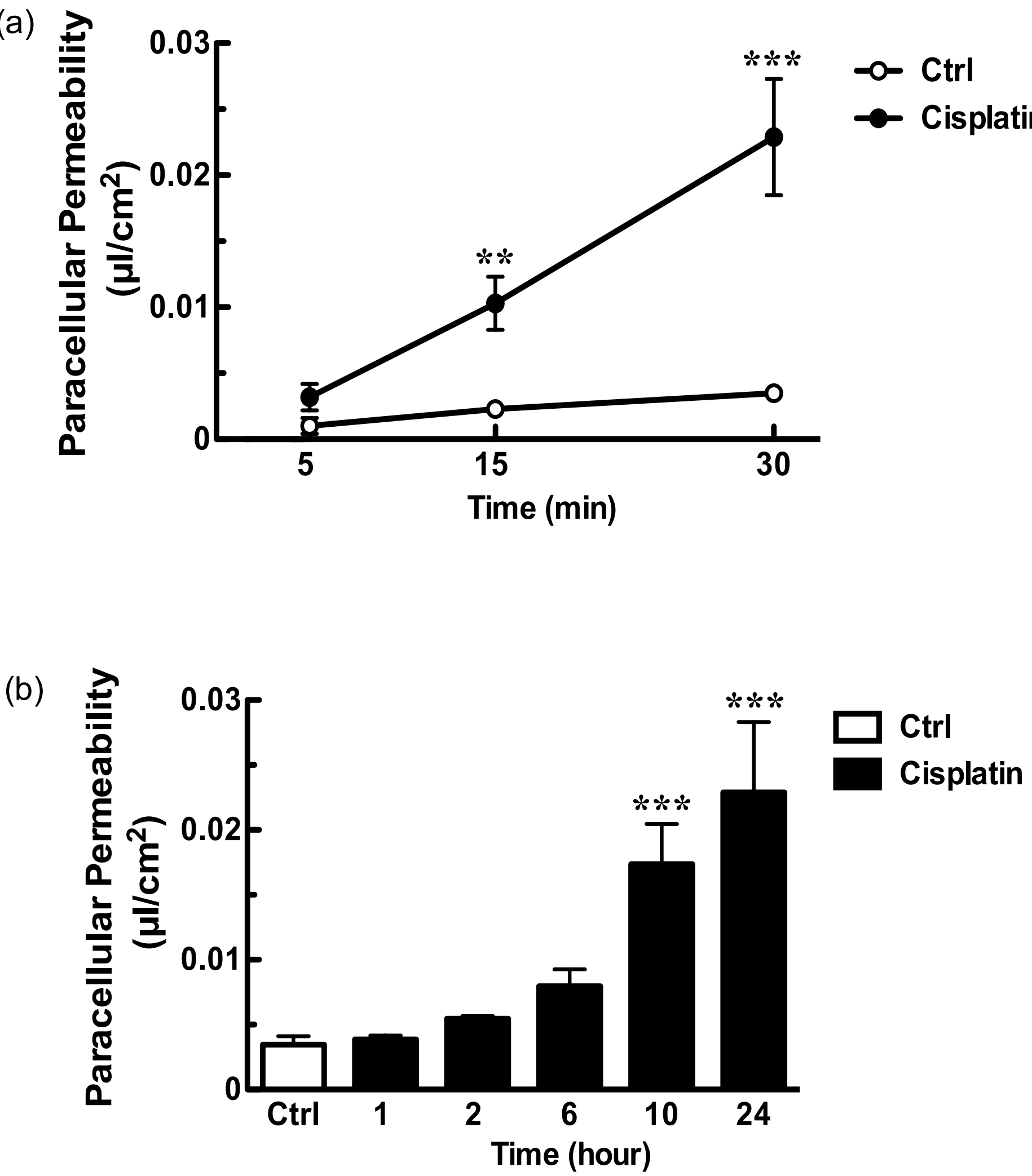
Figure 2

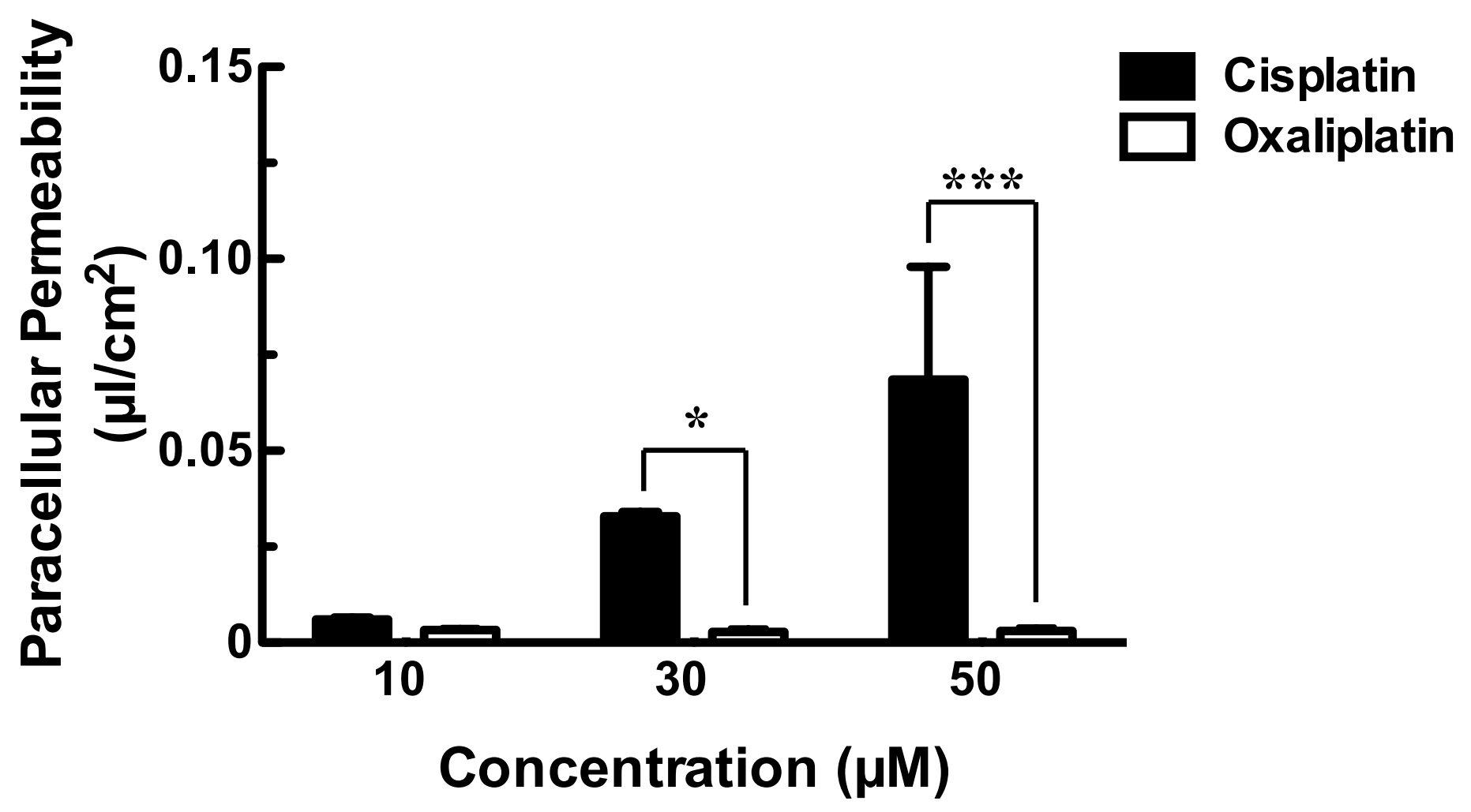


Figure 3

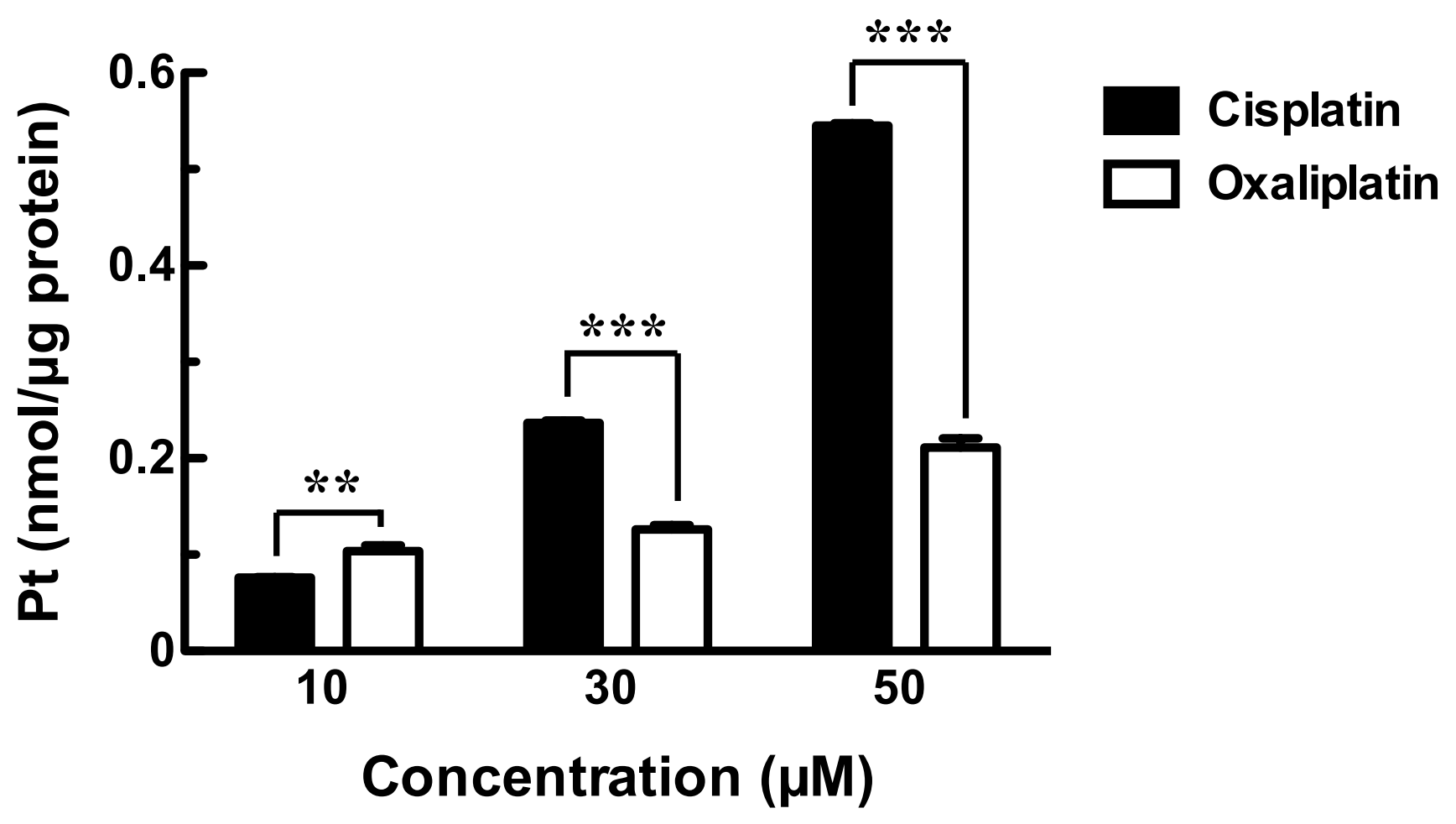


Figure 4
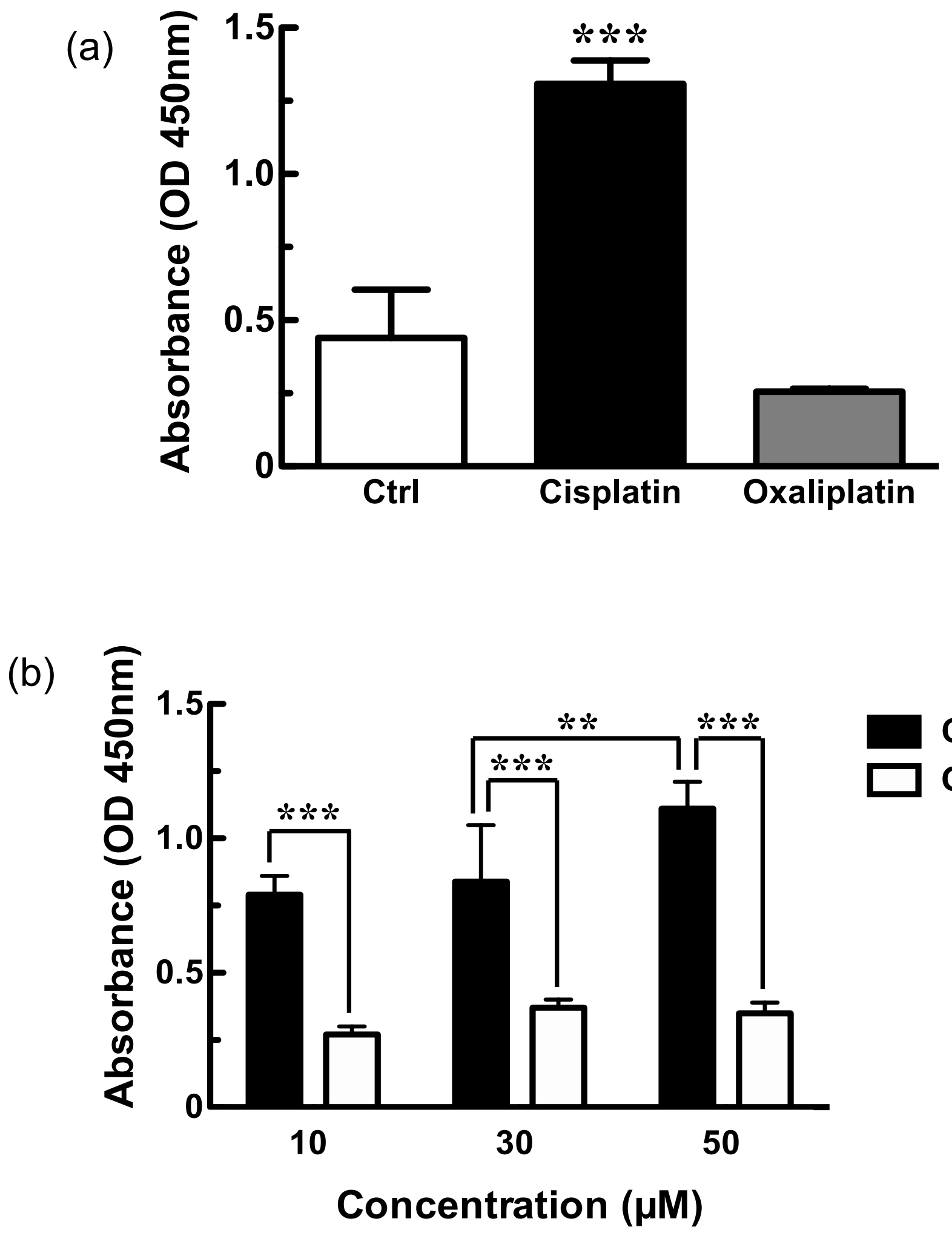

Cisplatin

$\square$ Oxaliplatin 


\section{Figure 5}

(a)

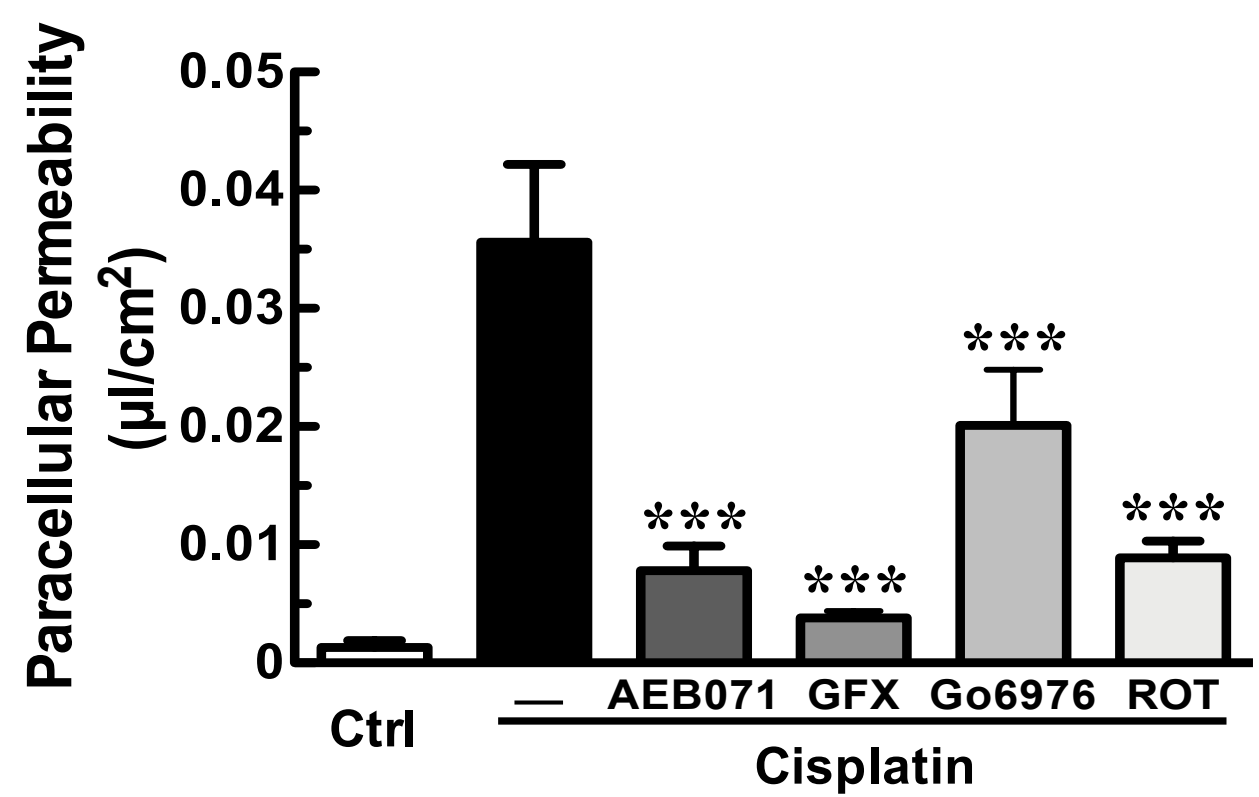

(b)

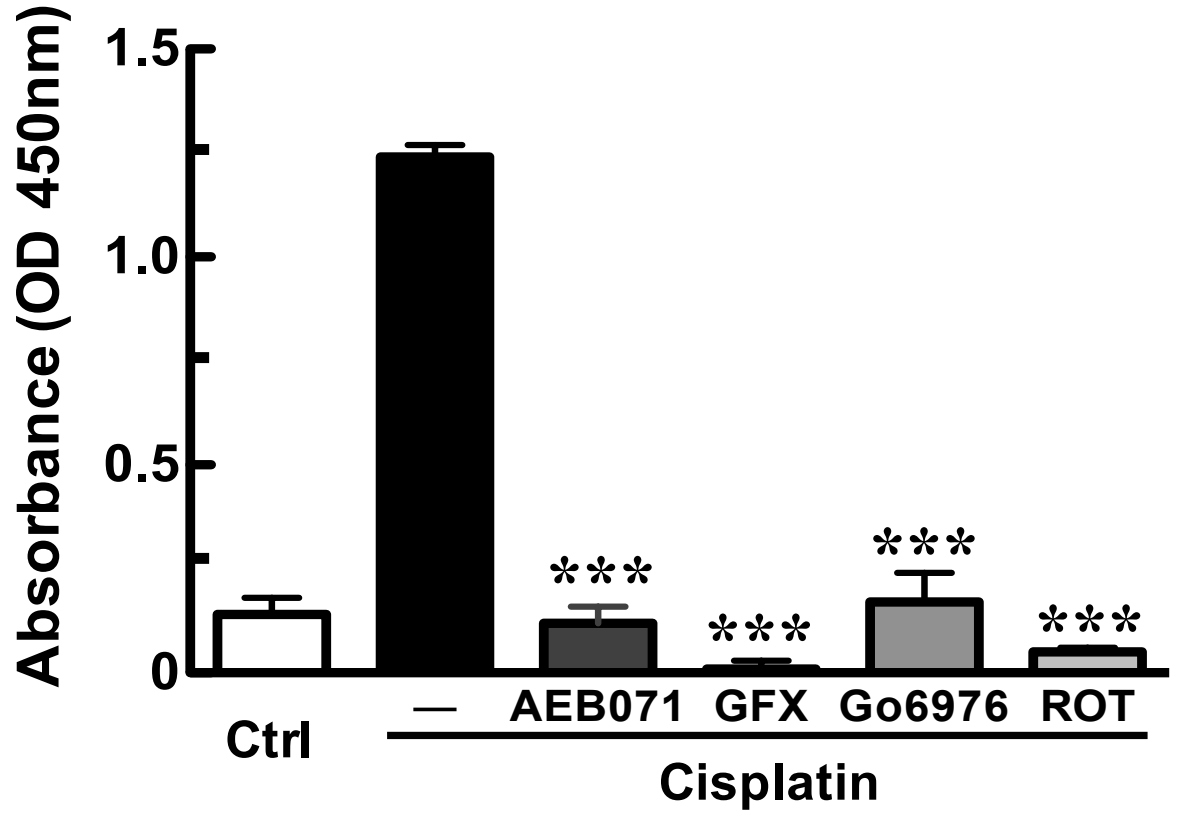


Figure 6

(a)

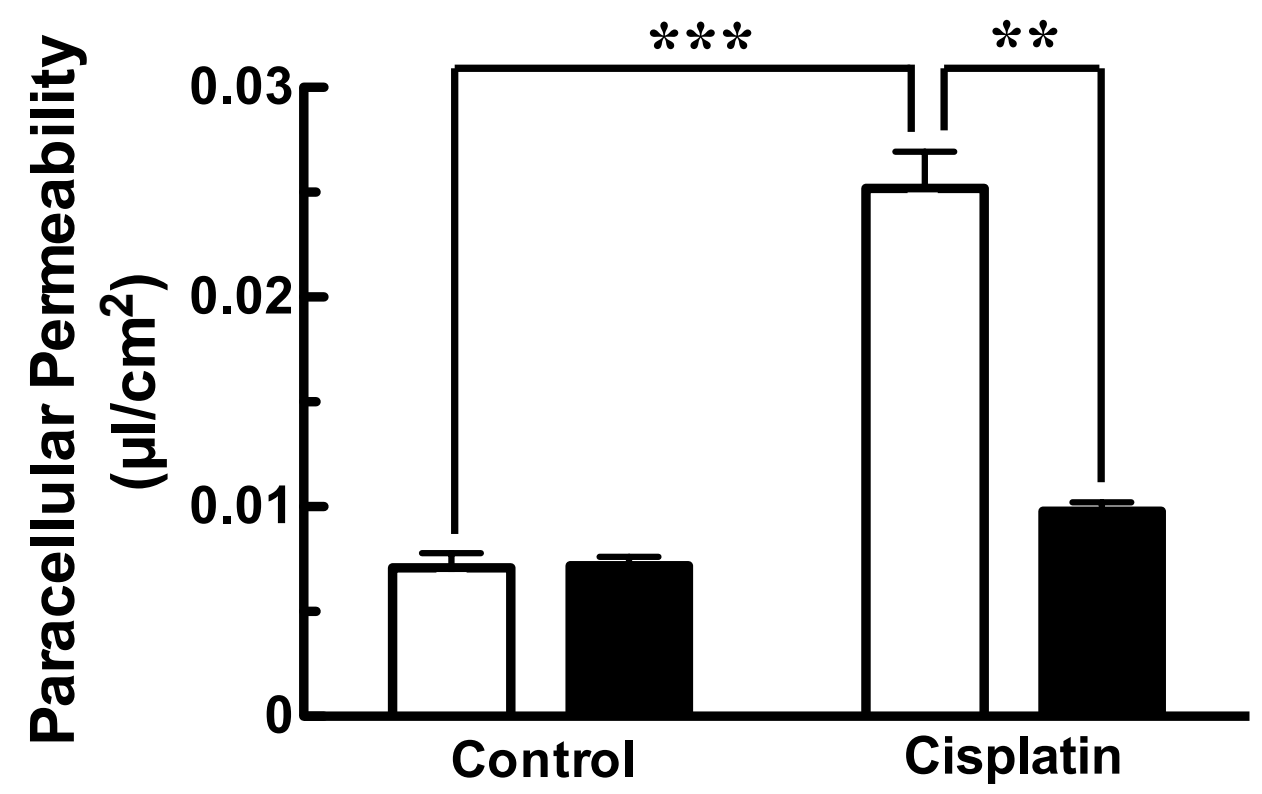

$\square$ Vehicle

Cimetidine

(b)

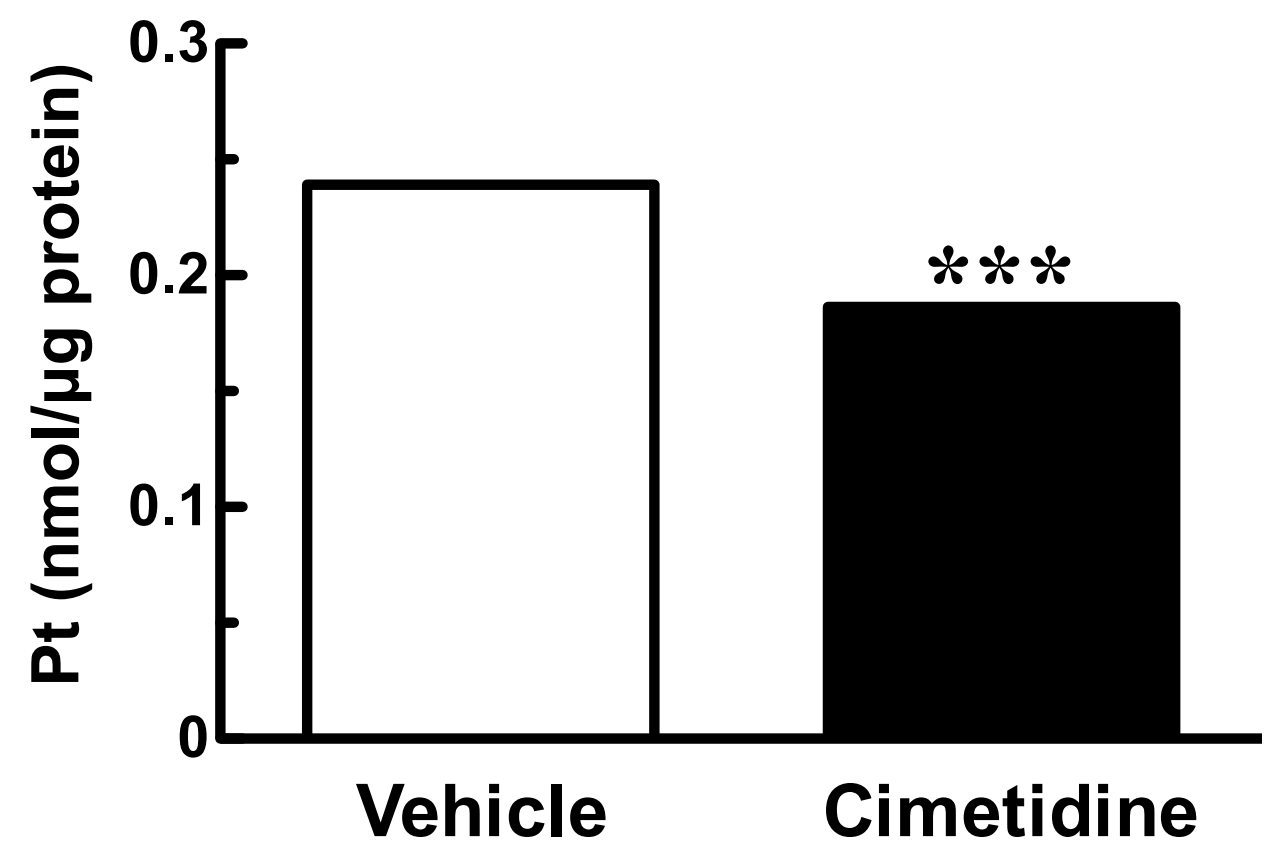

